Sādhanā Vol. 36, Part 3, June 2011, pp. 357-369. (c) Indian Academy of Sciences

\title{
Influence of free water content on the compressive mechanical behaviour of cement mortar under high strain rate
}

\author{
JIKAI ZHOU*, XUDONG CHEN, LONGQIANG WU and \\ XIAOWEI KAN
}

College of Civil and Transportation Engineering, Hohai University, Nanjing 210000, PR China

e-mail: jkzhou@hotmail.com

MS received 5 September 2009; revised 26 January 2011; accepted 4 February 2011

\begin{abstract}
The effect of free water content upon the compressive mechanical behaviour of cement mortar under high loading rate was studied. The uniaxial rapid compressive loading testing of a total of 30 specimens, nominally $37 \mathrm{~mm}$ in diameter and $18.5 \mathrm{~mm}$ in height, with five different saturations $(0 \%, 25 \%, 50 \%, 75 \%$ and $100 \%$, respectively) were executed in this paper. The technique 'Split Hopkinson pressure bar' (SHPB) was used. The impact velocity was $10 \mathrm{~m} / \mathrm{s}$ with the corresponding strain rate as $10^{2} / \mathrm{s}$. Water-cement ratio of 0.5 was used. The compressive behaviour of the materials was measured in terms of the maximum stress, Young's modulus, critical strain at maximum stress and ultimate strain at failure. The data obtained from test indicates that the similarity exists in the shape of strain-stress curves of cement mortars with different water content, the upward section of the stress-strain curve shows bilinear characteristics, while the descending stage (softening state) is almost linear. The dynamic compressive strength of cement mortar increased with the decreasing of water content, the dynamic compressive strength of the saturated specimens was $23 \%$ lower than that of the totally dry specimens. With an increase in water content, the Young's modulus first increases and then decreases, the Young's modulus of the saturated specimens was $23 \%$ lower than that of the totally dry specimens. No significant changes occurred in the critical and ultimate strain value as the water content is changed.
\end{abstract}

Keywords. Cement mortar; free water content; dynamic compressive mechanical behaviour; split Hopkinson pressure bar.

*For correspondence 


\section{Introduction}

For concrete structures (dam, bridge, offshore platform, etc.) operating underwater for a long period of time, the water content of concrete will have a certain influence on the mechanical behaviour.

The effect of water content on the static properties of concrete has been analysed for a while, and researchers have also conducted intensive studies achieving many satisfactory results (Price 1951; Bartlett \& Macgregor 1993; Hotta \& Takiguchi 1995). Meanwhile, experimental researches have also been carried out on the effect of water content on the dynamic behaviour of concrete. Rossi (1991) believed that water content was one of the main factors impacting the rate effect of materials. However, there seems to be no consensus as to whether an increase or decrease occur in the dynamic behaviour as the water content is changed. Rossi et al (1992), Cadoni et al (2001), Yan \& Lin (2006), Zhou (2007) have found that substantial strength increases for wet concrete in the regime with moderate strain rate, where dry concrete has been demonstrated to be relatively insensitive. Logunova et al (1994) achieved the same conclusion for compressive strength through tests. Reinhardt et al (1990) even thought that no strain rate effect could be detected in dry specimens under moderate strain rates $(0.5-1 / \mathrm{s})$ where a very remarkable strain rate effect only existed in the tensile strength of wet concrete. Zielinski et al (1981), Brara \& Klepaczko (2006) considered humidity condition had no effect on the tensile strength of concrete under high strain rate over $1 \mathrm{~s}^{-1}$, while Ross et al $(1995,1996)$, and Mori et al (2001) observed that above transition zone in strain rate, from 1 to 10/s, realized both dry and wet concrete showed obvious strain rate effect, which is that the dynamic tensile and compressive strength of wet concrete increased with increasing water content under a certain strain rate. Harris et al (2000) carried out dynamic mechanical tests on specimens obtained from dam cores, results of his study indicated that saturation ratio tended to decrease the static and dynamic compression strengths, and increased the static and dynamic splitting tensile strengths.

It is noteworthy that most of the above researchers simply categorized specimens as dry or wet instead of making a thorough study on the various water contents upon the dynamic behaviour of concrete, which needs to be studied further via experiment.

Cement mortar can be viewed as special concrete. On the one hand, the law of water content influence on dynamic mechanical behaviour of mortar can be applied in concrete. On the other hand, compared to normal concrete, cement mortar is uniform with small discreteness, which facilitates the research. Therefore, an experimental study on the influence of free water content on compressive mechanical behaviour of cement mortar under high strain rate was carried out.

\section{Experimental program}

\subsection{Split Hopkinson pressure bar (SHPB) and working principle}

Split Hopkinson Pressure Bar (SHPB) set-up places a relative short specimen in-between a long incident bar and a long output bar, as schematically shown in figure 1 . The impact of the striker bar on the incident bar results in a compressive incident pulse. At the input bar-specimen interface, part of the pulse is reflected as a tensile wave $\varepsilon_{\mathrm{R}}$ and the rest of the incident pulse penetrates the specimen as a compressive pulse $\varepsilon_{\mathrm{T}}$. Further, the resulting time-dependent strains are calculated from the voltage signals measured by strain gauges.

The analysis is based on two assumptions: (i) one-dimensional elastic stress wave theory is valid in pressure bars; (ii) stress and strain states within the specimen are uniaxial and uniform 


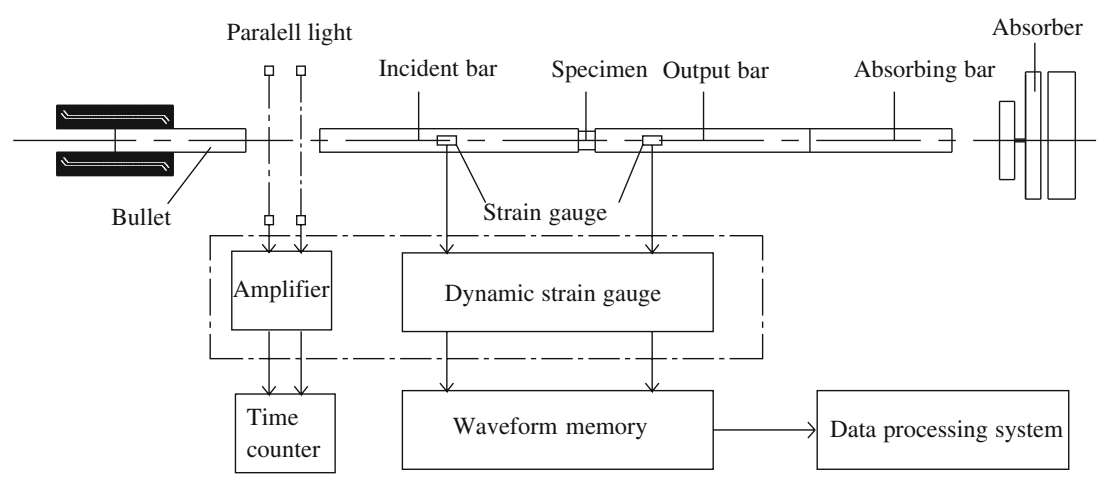

Figure 1. Configuration of the split Hopkinson bar.

(Albertini et al 1999). The resulting stress $\sigma_{\mathrm{s}}(t)$, strain $\varepsilon_{\mathrm{S}}(t)$ and strain rate $\dot{\varepsilon}$ of the specimen can be expressed as:

$$
\begin{gathered}
\sigma_{\mathrm{S}}(t)=E_{\mathrm{b}}\left(\frac{A_{\mathrm{b}}}{A_{\mathrm{S}}}\right) \varepsilon_{\mathrm{T}}(t) \\
\varepsilon_{\mathrm{S}}(t)=-\frac{2 C_{0}}{l} \int_{0}^{t} \varepsilon_{\mathrm{R}}(t) \mathrm{d} t \\
\dot{\varepsilon}=\frac{\mathrm{d} \varepsilon_{\mathrm{S}}(t)}{\mathrm{d} t}
\end{gathered}
$$

where $A_{\mathrm{b}}, E_{\mathrm{b}}, C_{0}$ are the cross-sectional area, the Young's modulus and the wave velocity of the bar material, and $l, A_{\mathrm{s}}$ are the length and cross-sectional area of the specimen.

\subsection{Specimens preparation}

The materials used were type $32.5 \mathrm{R}$ Portland cement and medium sand. The mix proportions of the cement mortar are as following: water/cement ratio $=0.5$, cement/sand ratio $=1: 2$. Cement mortar was poured in a steel mould with dimensions of $150 \mathrm{~mm} \times 150 \mathrm{~mm} \times 550 \mathrm{~mm}$. It is after $24 \mathrm{~h}$ curing that the moulds were removed off. The specimens were cured under a standard curing condition for 28 days. Then, the cores were drilled from the same matrix, the cylindrical specimens were made. The size of the specimen was $37 \mathrm{~mm}$-diameter and $18.5 \mathrm{~mm}$-height; corresponding length-diameter ratio is 0.5 . The compressive strength under static loading was 37.71 MPa.

\subsection{Test procedure}

First, experimental study on the law of water content of dry specimens changing with time during soaking processing was carried out. The cement mortar specimens were totally dried by oven drying at $105^{\circ} \mathrm{C}$. Five groups of mortar specimens with saturation of $0 \%, 25 \%, 50 \%, 75 \%$, and $100 \%$ were obtained after soaking. The number of specimens corresponding to one saturation was 6.

Then, uniaxial impact compressive loading tests of above cement mortar specimens were executed by the SHPB set-up. The strain rate was $1 \times 10^{2} / \mathrm{s}$. 


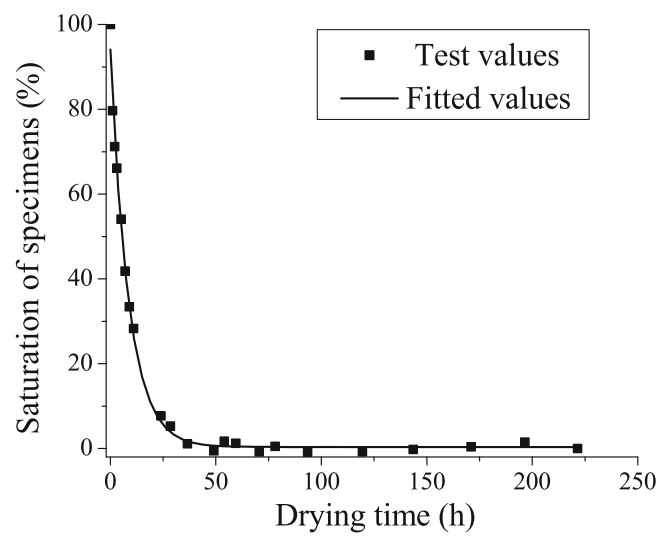

Figure 2. Saturation of specimens during drying process.

\section{Determination of saturation of cement mortar}

Sabir et al (1998) pointed out, that for avoiding the effect of the dry process on the solid phase of cement-based materials, an ideal arrangement is to dry the samples at an ambient temperature, but it takes a long time and would have extended the drying times in an uncontrollable manner. The drying method that was used in this study: oven-drying at $105^{\circ} \mathrm{C}$. For cement-based materials, the extreme drying time is 7 days (Galle 2001). When the mass of the specimen did not change after several weightings, the specimen could be considered totally dry. The specimens were encapsulated by plastic film to prevent being moistened.

The water content of cement mortar can be reflected by saturation. Saturation was calculated as follows:

$$
S_{\mathrm{r}}=\frac{W-W_{\mathrm{d}}}{W_{\mathrm{w}}-W_{\mathrm{d}}} \times 100 \%
$$

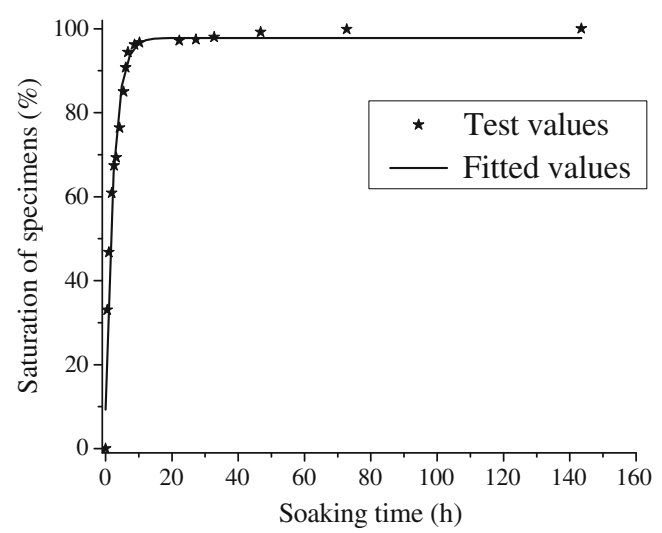

Figure 3. Saturation of specimens during soaking process. 
Table 1. The curve fitting parameters.

\begin{tabular}{lrccc}
\hline Condition & \multicolumn{1}{c}{$a$} & $b$ & $y_{0}$ & Correlation coefficient \\
\hline Drying & -93.82 & 8.67 & 0.35 & 0.99 \\
Soaking & 97.78 & 0.45 & - & 0.97 \\
\hline
\end{tabular}

where $S_{\mathrm{r}}$ is the saturation of the sample, $W$ is mass of the specimen $(\mathrm{g}), W_{\mathrm{w}}$ is the specimen water saturated mass $(\mathrm{g}), W_{\mathrm{d}}$ is the dried mass of a specimen $(\mathrm{g})$.

The dried specimens were soaked in water and timely measured. In order to control water content conveniently, the average values of saturation of the mortar specimens at each time were taken and fitted. The results showed that saturation of cement mortar during the drying or soaking process could be described by the exponential functions, which are plotted in figures 2 and 3 .

From the fitted curve, the formula of saturation of the cement mortar during soaking process can be obtained by Eq. (5).

$$
S_{\mathrm{r}}=a\left(1-e^{-b t}\right)
$$

The formula of saturation of the cement mortar during drying process can be obtained by Eq. (6).

$$
S_{\mathrm{r}}=a e^{-b t}+y_{0}
$$

where $a, b$ and $y_{0}$ are parameters, $t$ is soaking/drying time (h). The parameters are given in table 1 .

Using above laws, five groups of cement mortar specimens with different saturations $(0 \%$, $25 \%, 50 \%, 75 \%$ and $100 \%$ ) can be obtained.

\section{Test results}

The impact velocity of specimens was all $10 \mathrm{~m} / \mathrm{s}$ with a corresponding strain rate of $1 \times 10^{2} / \mathrm{s}$. The failure conditions of specimens were all crushed. From the specimens' fragments, it can be noticed that the inner humidity of specimens with different saturations differed. Influenced by saturation, the sounds during the test process were also different. The failure sound of a specimen with $0 \%$ saturation was clear, while the sound of a saturated specimen was clunk. The test results of specimens with different saturations are given in table 2. Stress-strain curves of specimens are plotted in figure 4.

Table 2. Test results of specimens with different saturations.

\begin{tabular}{lcccc}
\hline $\begin{array}{l}\text { Saturation of } \\
\text { specimen/\% }\end{array}$ & $\begin{array}{c}\text { Compressive } \\
\text { strength/MPa }\end{array}$ & $\begin{array}{c}\text { Young's } \\
\text { modulus/GPa }\end{array}$ & $\begin{array}{c}\text { Critical compressive } \\
\text { strain }\end{array}$ & $\begin{array}{c}\text { Ultimate compressive } \\
\text { strain }\end{array}$ \\
\hline 0 & 60.47 & 56.75 & 0.0064 & 0.032 \\
25 & 59.63 & 60.58 & 0.0053 & 0.035 \\
50 & 59.64 & 58.07 & 0.0054 & 0.036 \\
75 & 57.16 & 46.93 & 0.0060 & 0.032 \\
100 & 53.15 & 43.62 & 0.0059 & 0.037 \\
\hline
\end{tabular}




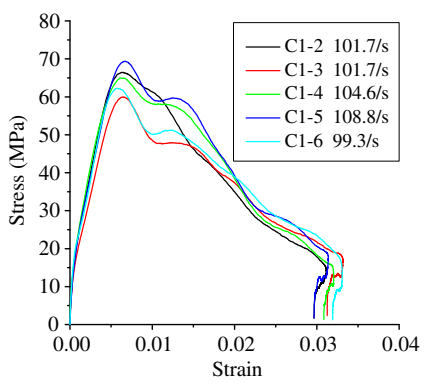

(a) $S_{r}=0 \%$

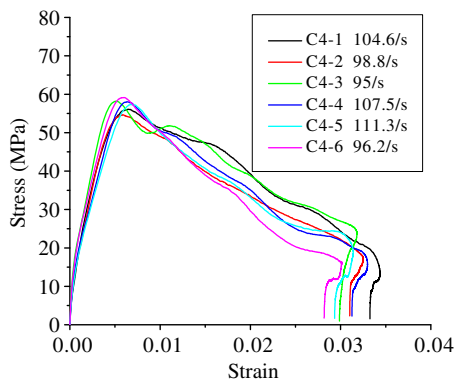

(d) $S_{r}=75 \%$

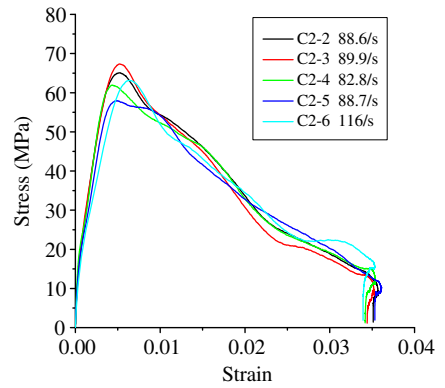

(b) $S_{r}=25 \%$

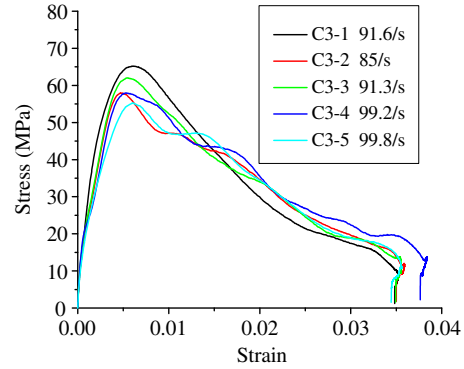

(c) $S_{r}=50 \%$

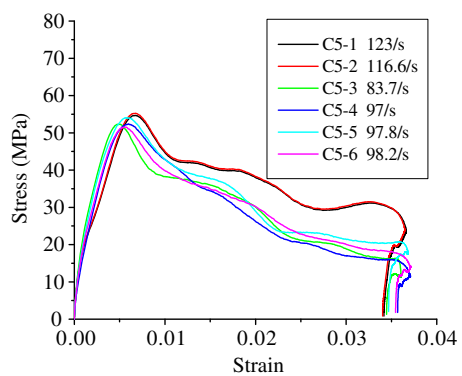

(e) $S_{r}=100 \%$

Figure 4. Dynamic stress-strain curves of specimens with different saturation.

\subsection{Dynamic stress-strain curves}

Observed from figure 4, it can be noticed that the shape of stress-strain curves of specimens with different saturation shares a good similarities. The averaging stress-strain curves of specimens are plotted in figure 5. It can be seen that the upward section of the stress-strain curve shows a bilinear characteristic, while the descending stage (softening state) is almost linear. When the compressive strain achieved is $0.030-0.040$, the specimens completely failed.

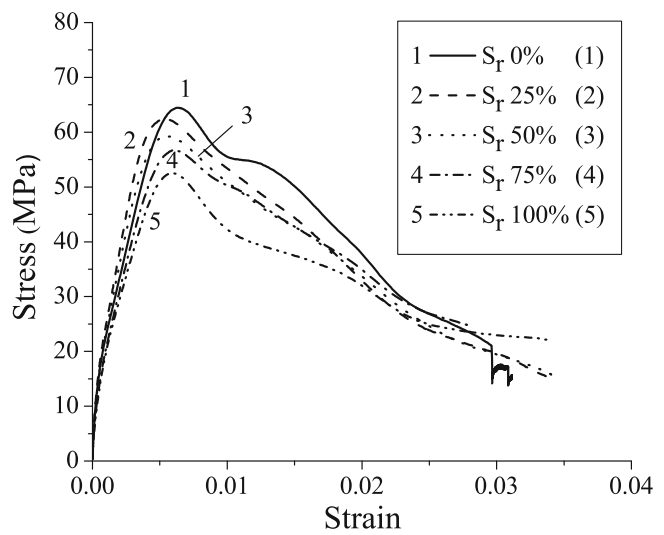

Figure 5. Comparison of dynamic stress-strain curves with different water content. 


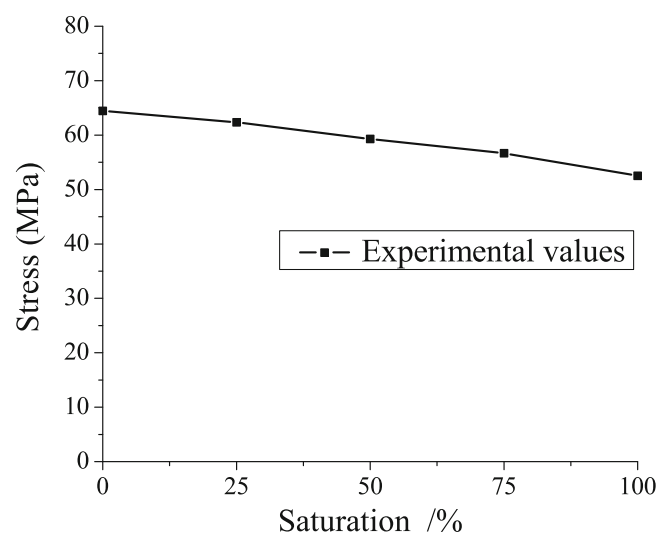

Figure 6. Influence of water content on dynamic compressive strength of cement mortar.

\subsection{Dynamic compressive strength}

The test results of dynamic compressive strength of cement mortar are given in table 2. Influence of the water content on the compressive strength of cement mortar is given in figure 6 .

As seen in figure 6, water content has a significant effect on the dynamic compressive strength of cement mortar specimens where the strengths decrease with the increasing of water content. The dynamic compressive strength of saturated specimens was $23 \%$ lower than that of totally dry specimens.

\subsection{Young's modulus}

Test results of Young's modulus specimens with different water content are given in table 2. The influence of water content on Young's modulus of cement mortar is plotted in figure 7.

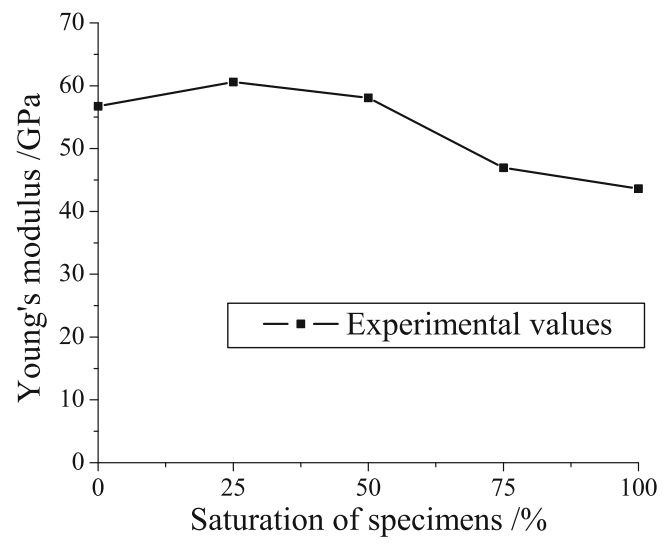

Figure 7. Influence of water content on dynamic Young's modulus of cement mortar. 


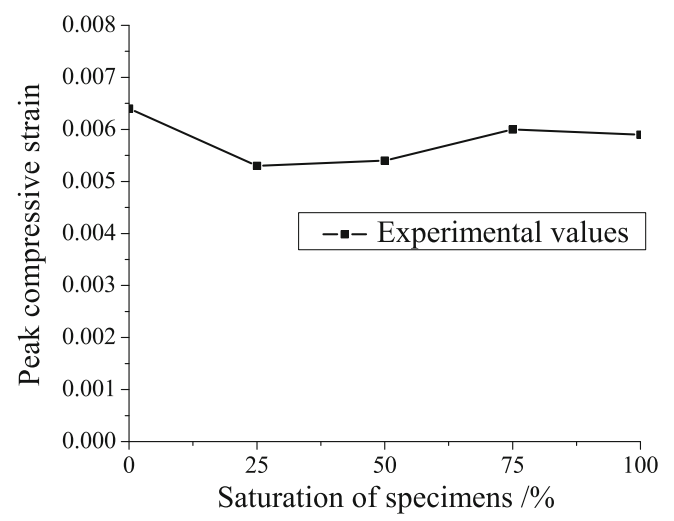

Figure 8. Influence of water content on dynamic critical compressive strain of cement mortar.

As seen in figure 7, compared to the totally dry condition, with the increasing of water content, Young's modulus of cement mortar increased at first and then decreased. The dynamic Young's modulus of the saturated specimens was $23 \%$ lower than that of the totally dry specimens.

\subsection{Critical compressive strain and ultimate compressive strain}

Test results of critical compressive strain and ultimate compressive strain of specimens with different water content are given in table 2. The influence of water content on critical compressive strain and ultimate compressive strain of cement mortar are plotted in figures 8 and 9 , respectively. Under a high strain rate, the critical compressive strains of cement mortar with different water contents are between 0.0053 and 0.0064 while the ultimate compressive strains are between 0.032 and 0.037 , with small range change. Considering the discreteness of the specimen material and test results from SHPB, it can be deduced that the critical compressive strain and ultimate compressive strain of cement mortar do not change with water content.

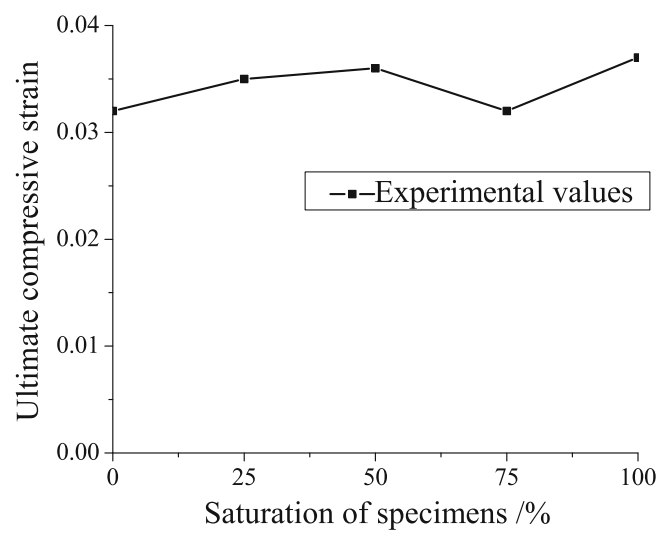

Figure 9. Influence of water content on dynamic ultimate compressive strain of cement mortar. 


\section{Discussions}

\subsection{Drying method}

It is generally considered that, at $105^{\circ} \mathrm{C}$, only free water-evaporable water-was removed from pore structure. On the other hand, this procedure is usually selected mainly because it is quicker drying method. However, Konecny \& Naqvi (1993) found that in over drying, pores in hardened cement pastes were damaged, and oven drying at $105^{\circ} \mathrm{C}$ partially dehydrated the $\mathrm{C}-\mathrm{S}-\mathrm{H}$. Feldman \& Beaudoin (1991) found that after oven drying cracks were formed in the microstructure of the cement-based materials with the crack density increasing as the drying conditions became more severe. Galle (2001) also concluded that oven drying at $60^{\circ} \mathrm{C}$ and $105^{\circ} \mathrm{C}$ are responsible for a large capillary porosity that can be attributed to capillary stress, cement hydrates (ettringite, Afm, C-S-H) desiccation and potential microcrack generation in relationship with internal thermohydric stress.

From literature review, it can be found that damage due to drying at $105^{\circ} \mathrm{C}$ is likely to occur although the small maximum grain size of $2 \mathrm{~mm}$ prevents the mortar from developing large bond cracks between sand and matrix. It is expected that small cracks may have occurred and that the pores of the matrix region became larger than before drying (Collier et al 2008). Both effects lead to a certain reduction of strength which is difficult to quantify. Cracking can be avoided if the environmental humidity (at $20^{\circ} \mathrm{C}$ ) is decreased gradually and sufficiently slowly, and the specimens have to be unreasonably thin (about $1 \mathrm{~mm}$ ) to make this approach possible (Bazant \& Raftshol 1982). However, it has been shown that fewer cracks could be observed at the surface of the specimen immersed again in water, compared with that just after drying (Hotta \& Takiguchi 1995). Cracking can also be eliminated by loading which produces sufficient compression (Bazant \& Raftshol 1982).

\subsection{Lateral confinement in SHPB tests}

Compared with static strength value of $37.1 \mathrm{MPa}$, it can be found that the dynamic compressive strength of mortar increased greatly under high strain rate. The physical mechanisms about the strain rate effect on dynamic strength of concrete have not been fully understood. At least, two factors, the viscoelastic character of the hardened cement paste and the time-dependent microcrack growth, may contribute to the macroscopic sensitivity to strain rate (Rossi 1991). A very important factor, which may cause the dynamic strength enhancement of concrete with increase of strain rate, is the lateral inertia in a SHPB test. The lateral confinement comes from both the contact surface restriction and the lateral inertia during rapid compression. The influence of the lateral confinement on SHPB measurement is normally ignored for metallic specimens because the contact friction is ultimately reduced using lubricant and the lateral inertia induced lateral confinement does not influence the flow stress due to an important fact that the metal plasticity is hydrostatic stress independent (Zhang et al 2010). However, the stress response of concrete-like material is hydrostatic stress dependent, and therefore, it has completely different response to the lateral confinement. The fact is that the compressive strength of cement-based material can be largely enhanced by the lateral confinement.

There are several publications to note this issue and study the development of the lateral confinement in a SHPB test for cement-based materials. In their literature review about the compressive behaviour of concrete at high strain rates, Bischoff \& Perry (1991) summarized the scatter evidences about the lateral inertia confinement influence on the compressive strength of concrete-like materials in a dynamic test. This problem was simulated by Donze et al (1999) 
and Hentz et al (2004) using a 3D discrete element method where the input data are the velocities at the both ends of the cylindrical specimen and the output data are the computed forces on these two end faces. It shows that the transmitted force through the concrete cylinder could be increased, thus, leading to an apparent strain rate effect that is actually due to the lateral inertial confinement. Recent work by Zhou \& Hao (2008) also provide computational confirmation of inertial confinement contributing to the observed increase in dynamic strength in unconfined compression tests.

These limited studies by Bischoff \& Perry (1991) claim that strength enhancement may be caused partly by a transition from a state of uniaxial stress to uniaxial strain. When the stress state in the cylindrical specimen in a SHPB test is deviated from the uniaxial stress state, the apparent compressive strength will definitely increase if the tested material is hydrostatic stress dependent.

Further studies are necessary to confirm this explanation for the strain rate sensitivity of cement-based materials at high strain rates and locate the transition point of apparent strain-rate sensitivity for each type of cement-based materials. Both experimental and numerical studies may offer more information to separate apparent strain rate effects from genuine strain rate effects in dynamic material property tests, which is important for material model intensification.

\subsection{Effect of water content on dynamic compressive behaviour}

From test results, it seems that the water content has a major influence on the compressive behaviour mortar under high strain rate since all tests were performed at the same strain rate (approximatively 100/s). In the moderate regime, the free water in the micro-pores is assumed to exhibit the so-called Stefan-effect causing loading rate (Rossi et al 1992).

The test results showed that the strength decreases with the increasing of water content. In fact, with the decreasing of water content, the drying shrinkage that arises (Bazant \& Wittmann 1982). This phenomenon results in capillary pressure (or suction) increase, surface energy variations and disjunction pressure variations (Kolver \& Zhutovsky 2006). On the other hand, the rise of capillary suction brings about increase in uniaxial and triaxial compressive strength of concrete (Vu et al 2009a). Increase in capillary suction leads to a compression of the solid skeleton which is similar to a 'pre-stressing' of mortar acting like confining pressure. Therefore, there will be a decrease in compressive strength with water content increasing.

Furthermore, when mortar loses water it shrinks, and when it gains water it swells. Although these volume change may be closely related to micro-capillarity action in the pores and interlayer spaces, this effect is considered separately from the previous discussion of capillarity. Whenever these volume changes are not uniformly distributed across a section, differential volume change strains and stresses are generated, exactly as in the case of thermal stresses. In such a manner a specimen can be prestressed in either tension or compression. Which then induces an increase in sample strength and a decrease in Young's modulus with water content increasing. This was confirmed also from other researcher's results (Radiy \& Richards 1973; Vu et al 2009a).

Severe dynamic loading, such as that produced by near-field denotation or ballistic impacts on concrete infrastructure, can generate very high-intensity triaxial stress states in concrete material (Vu et al 2009b, c). The behaviour of dried mortars and concrete under static triaxial loading has been intensively studied (Gabet et al 2008; Vu et al 2009a). Vu et al (2009a) have shown that the saturation ratio exerts a major influence on concrete behaviour, particularly on both the concrete strength capacity and shape of the limit state curve for saturation ratios above $50 \%$. The behaviour of concrete under high pressure and dynamic loading is experimentally investigated by Forquin et al (2010). It is subjected to dynamic (with strain rates in the range from $6 \mathrm{~s}^{-1}$ to 200/s) 
axial compressive loadings. They show exactly the same conclusion as Vu et al (2009a). This confirms that the saturation ratio has a major influence on the confined compression behaviour.

However, Vu et al (2009a) have different conclusions from the test results in this paper since the relative difference of compressive strength is much more important than the one given in table 2 . The pore pressure is defined as the pressure in the free water in the centres of the capillary pores and air bubbles. The free water can become pressurized under external loading or by forced water penetration (i. e., water under pressure). For confined compression tests, saturated materials under compressive loading, the loading does not only result in compression of the solid material. Also the pore spaces, and thus the pore water will be compressed. Since the material in confined tests is impermeable, the water can not be drained from the pores and pore pressures in the capillary pores existed. Also though pore air (in the dry or unsaturated porous materials) will be compressed, it is claimed that the compressibility of the air is too high to generate noticeable pore air pressures (Skoczylas et al 2007). The term pore pressure is therefore restricted to denote pressures in the pore water. In this study, the material is never fully saturated under no confined dynamic compression, and the pore pressure has no influence on the test results.

This ressults from the article, in our opinion could draw a final conclusion about the effect of free water on the dynamic compressive strength. However, further studies are still necessary for understanding about the strain-rate effect on the ultimate and uniaxial compressive strength of cement-based materials with different water content in SHPB tests.

\section{Concluding remarks}

By applying SHPB set-up, the uniaxial rapid compressive loading tests of 30 total specimens with five saturations $(0 \%, 25 \%, 50 \%, 75 \%$ and $100 \%$, respectively) were executed with a strain rate of $1 \times 10^{2} / \mathrm{s}$. From test results, the following conclusions are drawn.

(i) The dynamic compressive strength of cement mortar increased with the decreasing of water content. The dynamic compressive strength of saturated specimens was $23 \%$ lower than that of totally dry specimens.

(ii) With an increase in water content, the Young's modulus first increased and then decreased, the Young's modulus of the saturated specimens was lower $23 \%$ than that of the totally dry specimens.

(iii) No significant changes occur in the critical and ultimate strain value as the water content is changed. The specimens failed eventually when the strain achieved 0.030-0.040.

(iv) Similarity exists in the shape of strain-stress curve of cement mortars with different water content. The upward section of stress-strain curve shows a bilinear characteristic, while the descending stage (softening state) is almost linear.

This work was sponsored by the National Natural Science Foundation of China (No. 90510017 , No. 50979032, No. 91010006), which is gratefully appreciated.

\section{List of symbols}

$a, b$ and $\mathrm{y}_{0}$ parameters;

$A_{\mathrm{b}}$ cross-sectional area of the bar;

$A_{\mathrm{s}}$ cross-sectional area of the specimen;

$C_{0}$ wave velocity of the bar; 


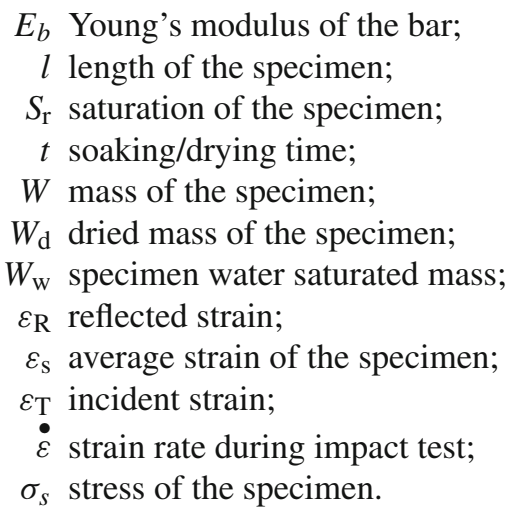

\section{References}

Albertini C, Cadoni E and Labibes K 1999 Study of the mechanical properties of plain concrete under dynamic loading. Exp. Mech. 39: 137-141

Bartlett F M and Macgregor J G 1993 Effect of moisture condition on concrete core strengths. ACI Mater. J. $91: 227-236$

Bazant Z P and Raftshol W J 1982 Effect of cracking in drying and shrinkage specimens. Cement Concrete Res. 12: 209-226

Bazant Z P and Wittman F H 1982 Creep and shrinkage in concrete structures (London: John Wiley \& Sons)

Bischoff P H and Perry S H 1991 Compressive behaviour of concrete at high strain rates. Mater. Struct. 24: 425-450

Brara A and Klepaczko J R 2006 Experimental characterization of concrete in dynamic tension. Mech. Mater. 38: 253-267

Cadoni E, Labibes K, Albertini C, Berra M and Giangrasso M 2001 Strain-rate effect on the tensile behaviour of concrete at different relative humidity levels. Mater. Struct. 34: 21-26

Collier N C, Sharp J H, Milestone N B, Hill J and Godfrey I H 2008 The influence of water removal techniques on the compositions and microstructure of hardened cement pastes. Cement Concrete Res. 38: 737-744

Donze F V, Magnier S A, Daudeville L, Mariotti C and Davenne L 1999. Numerical study of compressive behavior of concrete at high strain rates. J. Eng. Mech., Am. Soc. Civil Eng. 125: 1154-1163

Feldman R F and Beaudoin J J 1991 Pretreatment of hardened cement paste for mercury intrusion measurements. Cement Concrete Res. 21: 297-308

Forquin P, Safa K and Gary G 2010 Influence of free water on the quasi-static and dynamic strength of concrete in confined compression tests. Cement Concrete Res. 40: 321-333

Galle C 2001 Effect of drying on cement-based materials pore structure as identified by mercury intrusion porosimetry, A comparative study between oven-, vacuum-, and freeze-drying. Cement Concrete Res. 31: $1467-1477$

Gabet T, Malecot Y and Daudeville L 2008 Triaxial behaviour of concrete under high stresses: Influence of the loading path on compaction and limit states. Cement Concrete Res. 38: 403-412

Harris D W, Mohorovic C E and Dolen T P 2000 Dynamic properties of mass concrete obtained from dam cores. ACI Mater. J. 97(3): 290-296

Hentz S, Donze F V and Daudeville L 2004 Discrete element modelling of concrete submitted to dynamic loading at high strain rates. Comput. Struct. 82: 2509-2524

Hotta H and Takiguchi K 1995 Influence of drying and water supplying after drying on tensile strength of cement mortar. Nucl. Eng. Des. 156(6): 218-228 
Kolver K and Zhutovsky S 2006 Overview and future trends of shrinkage research. Mater. Struct. 39: 827-847

Konecny L and Naqvi S J 1993 The effect of different drying techniques on the pore size distribution of blended cement mortars. Cem. Conc. Res. 23: 1223-1228

Logunova V A, Rudenko V V, Radionov A K and Sokolov I B 1994 Dynamic strength of concrete. Hydrotech. Constr. 28(6): 313-316

Mori K, Uebayashi K, Fujikake K, Ohno T and Satoh H 2001 Influence of Moisture content on compressive and tensile strength properties of concrete under high strain-rates. J. Struct. Eng. A 47: 1673-1681

Price W H 1951 Fators influencing concrete strength. J. Am. Concrete Inst. 47: 417-432

Radjy F and Richards C W 1973 Effect of curing and heat treatment history on the dynamic mechanical response and the pore structure of hardened cement paste. Cement Concrete Res. 3: 7-21

Reinhardt H W, Rossi P and van Mier J G M 1990 Joint investigation of concrete at high rates of loading. Mater. Struct. 23: 213-216

Ross C A, Tedesco J W and Kuennen S T 1995 Effects of strain rate on concrete strength. ACI Mater. J. 92: $37-47$

Ross C A, Jerome D M, Tedesco J W and Hughes M L 1996 Moisture and strain rate effects on concrete strength. ACI Mater. J. 93: 293-300

Rossi P 1991 A physical phenomen which can explain the mechanical behaviour of concrete under high stain rates. Mater. Struct. 24: 422-424

Rossi P, Van Mier J G M, Boulay C and Maou F L 1992 The dynamic behavior of concrete: influence of free water. Mater. Struct. 25: 509-514

Sabir B B, Wild S and O'Farrel M 1998 A water sorptivity test for mortar and concrete. Mater. Struct. 31: $568-574$

Skoczylas F, Burlion N and Yurtdas I 2007 About drying effects and poro-mechanical behaviour of mortars. Cement Concrete Comp. 29: 383-390

Vu X H, Malecot Y, Daudeville L and Buzaud D 2009a Experimental analysis of concrete behavior under high confinement: Effect of the saturation ratio. Int. J. Solid Struct. 46: 1105-1120

Vu X H, Malecot Y and Daudevile L 2009b Strain measurements on porous concrete samples for triaxial compression and extension tests under very high confinement. J. Strain Anal. Eng. 44: 633-657

Vu X H, Malecot Y, Daudeville L and Buzaud E 2009c Effect of the water/cement ratio on concrete behavior under extreme loading. Int. J. Numer. Anal. Met. 33: 1867-1888

Yan D M and Lin G 2006 Dynamic properties of concrete in direct tension. Cement Concrete Res. 36: $1371-1378$

Zhang M, Li Q M, Huang F L and Lu Y B 2010 Inertia-induced radial confinement in an elastic tubular specimen subjected to axial strain acceleration. Int. J. Solids Struct. 37: 459-464

Zhou J K 2007 Mechanism and test study on dynamic flexural-tensile mechanic behaviour of fully-grade concrete in high arch dam. Ph.D Thesis. Hohai University, Nanjing, China

Zhou X Q and Hao H 2008 Modeling of compressive behaviour of concrete-like materials at high strain rate. Int. J. Solid Struct. 45: 4648-4661

Zielinski A J, Reinhardt H W and Kormeling H A 1981 Experiments on concrete under impact tensile loading. Mater. Struct. 14: 103-112 